\title{
The development of a nitrogen dioxide sonde
}

\author{
W. W. Sluis ${ }^{1}$, M. A. F. Allaart ${ }^{1}$, A. J. M. Piters ${ }^{1}$, and L. F. L. Gast ${ }^{2}$ \\ ${ }^{1}$ Royal Netherlands Meteorological Institute (KNMI), De Bilt, The Netherlands \\ ${ }^{2}$ The National Institute for Public Health and the Environment (RIVM), Environment and Safety Division (MEV), \\ Centre for Environmental Monitoring (CMM), Bilthoven, The Netherlands
}

Received: 29 March 2010 - Published in Atmos. Meas. Tech. Discuss.: 2 July 2010

Revised: 28 October 2010 - Accepted: 29 October 2010 - Published: 16 December 2010

\begin{abstract}
A growing number of space-borne instruments measures nitrogen dioxide $\left(\mathrm{NO}_{2}\right)$ concentrations in the troposphere, but validation of these instruments is hampered by the lack of ground-based and in situ profile measurements.
\end{abstract}

The Royal Netherlands Meteorological Institute (KNMI) has developed a working $\mathrm{NO}_{2}$ sonde. The sonde is attached to a small meteorological balloon and measures a tropospheric $\mathrm{NO}_{2}$ profile. The $\mathrm{NO}_{2}$ sonde has a vertical resolution of $5 \mathrm{~m}$ and a measurement range between 1 and $100 \mathrm{ppbv}$. The instrument is light in weight $(0.7 \mathrm{~kg})$, cheap (disposable), energy efficient and not harmful to the environment or the person who finds the package after use. The sonde uses the chemiluminescent reaction of $\mathrm{NO}_{2}$ in an aqueous luminol solution. The $\mathrm{NO}_{2}$-luminol reaction produces faint blue/purple light (at about $425 \mathrm{~nm}$ ), which is detected by an array of silicon photodiodes. The luminol solution is optimised to be specific to $\mathrm{NO}_{2}$.

An on-ground comparison with measurements from a Photolytic Analyser of The National Institute for Public Health and the Environment (RIVM) shows that both instruments measure similar $\mathrm{NO}_{2}$ variations in ambient air.

During the Cabauw Intercomparison campaign of Nitrogen Dioxide measuring instruments (CINDI) in June/July 2009, six vertical profiles of $\mathrm{NO}_{2}$ from the ground to a $5 \mathrm{~km}$ altitude were measured, which clearly show that the largest amount of $\mathrm{NO}_{2}$ is measured in the boundary layer. The measured boundary layer heights of the $\mathrm{NO}_{2}$ sonde are in good agreement with boundary layer heights determined by a LD40 Ceilometer at Cabauw.

\section{Introduction}

Nitrogen dioxide $\left(\mathrm{NO}_{2}\right)$ is an important pollutant in the atmosphere, because it is toxic for living species, it forms photochemical ozone $\left(\mathrm{O}_{3}\right)$ and acid rain in the form of nitric acid $\left(\mathrm{HNO}_{3}\right)$. Nitrogen dioxide is a member of the nitrogen oxides ( $\mathrm{NO}$ and $\mathrm{NO}_{2}$ ). In the troposphere they are typically formed as a by-product of the combustion of fossil fuels at high temperatures.

A growing number of space-borne instruments measures nitrogen dioxide concentrations in the atmosphere, but validation of these instruments is hampered by lack of groundbased and in situ profile measurements of $\mathrm{NO}_{2}$. This was one of the conclusions from the Atmospheric Composition Change the European Network of Excellence - Accent Troposat-2 (ACCENT-AT2) supported workshop on "Tropospheric $\mathrm{NO}_{2}$ measured by satellites", at KNMI, De Bilt, The Netherlands from 10 to 12 September $2007^{1}$.

In situ profile measurements have been performed in a number of aircraft campaigns (e.g., Boersma et al., 2008; Kelly et al., 1990). A disadvantage of aircraft measurements is, apart from their relatively high cost, that the lower few hundred metres of the atmosphere, which contain a significant part of the tropospheric $\mathrm{NO}_{2}$, are difficult to reach.

The current study is aimed at the development of an instrument that can measure $\mathrm{NO}_{2}$ in situ, which is cheap (disposable), light in weight, energy efficient, can provide profiles up to $30 \mathrm{~km}$ altitude and is not harmful for the environment or the finder of the package. Such an instrument can be launched with a normal weather balloon, typically used for ozone sondes.

\footnotetext{
$1_{\text {This report can be found at http://www.knmi.nl/research/climate_observations/ }}$ events/no2_workshop/presentations/NO2_report.pdf.

Correspondence to: W. W. Sluis

(sluis@knmi.nl) 
Existing in situ measurement techniques to measure $\mathrm{NO}_{2}$ can be divided in three categories: laser-based techniques, differential optical absorption spectroscopy and chemiluminescence.

Laser-based techniques to measure $\mathrm{NO}_{2}$ include laserinduced fluorescence (LIF; Matsumoto et al., 2001), tunable diode laser absorption spectroscopy (TDLAS; Li et al., 2004), cavity enhanced absorption spectroscopy (CEAS; Kebabian et al., 2005) and photo-acoustic spectroscopy (Mitrayana et al., 2007). Laser-based techniques are not considered for use on a disposable weather balloon, because these instruments are too large, heavy, energy-consuming and expensive.

Differential optical absorption spectroscopy (DOAS; Platt and Perner, 1980) requires an energy consuming broad-band light source and a long optical path. Therefore, also this technique is not a good candidate to use with a weather balloon.

Chemiluminescence techniques can be subdivided in gasphase and liquid-phase chemiluminescence. The first uses a catalytic or photolytic converter to reduce $\mathrm{NO}_{2}$ to $\mathrm{NO}$ which is then mixed with ozone (Steinbacher et al., 2007; Parrish et al., 1990). The reaction of $\mathrm{NO}$ with $\mathrm{O}_{3}$ produces light, which is subsequently measured. The M200E Photolytic Analyser (mentioned in Sect. 5) and the TEI 42 TL chemiluminescence analyser with blue light converter (mentioned in Sect. 7) are examples of this technique. Gas-phase chemiluminescence is widely used in $\mathrm{NO}_{2}$ monitoring networks. Both types of converters are energy-consuming, again making them less suitable for use on a weather balloon.

In the liquid-phase chemiluminescence technique light is emitted by the chemical reaction of luminol with $\mathrm{NO}_{2}$. The commercially available Luminox LMA-3 instrument uses this technique combined with a photomultiplier tube (Kelly et al., 1990). This technique has been used in earlier attempts to make a light-weight instrument which can be launched with a balloon.

Hasinoff (1997) used an $\mathrm{NO}_{2}$ sonde, as described by Pisano et al. (1996), in a field study at Kejimkujik National Park in Nova Scotia in 1996. The instrument weighs $1195 \mathrm{~kg}$, and uses the luminol- $\mathrm{NO}_{2}$ reaction. The emitted light of the luminol- $\mathrm{NO}_{2}$ reaction is detected by a photomultiplier tube. Hasinoff (1997) measured $\mathrm{NO}_{2}$ profiles up to $1 \mathrm{~km}$ altitude while the instrument was suspended from a tethered balloon. She recommends, for future studies, designing and building a more reliable and more user-friendly $\mathrm{NO}_{2}$ sonde, as this instrument was found to be extremely difficult to use.

Sitnikov et al. (2005) build a chemiluminescent balloonborne instrument called $\mathrm{NaDA}$ to measure $\mathrm{NO}_{2}$. The $\mathrm{NaDA}$ instrument uses the chemiluminescent reaction of luminol with $\mathrm{NO}_{2}$. The instrument weighs approximately $1 \mathrm{~kg}$, and uses a photomultiplier tube, making it too heavy and too expensive for use in a disposable sonde.

The newly developed $\mathrm{NO}_{2}$ sonde does not make use of a photomultiplier tube. Instead, an array of silicon photodiodes is used to detect the light from the chemiluminescent reaction. Photodiodes are light in weight and do not require power or a high voltage. An amplifier is used to enhance the rather weak signal from photodiodes. This amplifier, together with the reaction vessel and photodiodes, is placed in a metal can to reduce electrostatic interference.

The luminol solution in the $\mathrm{NO}_{2}$ sonde has been optimised for the reaction with $\mathrm{NO}_{2}$ following Mikuška et al. (2000). They studied the application of surfactants and complexones for the suppression of interferences from other pollutants in the determination of $\mathrm{NO}_{2}$ with a Chemiluminescence Aerosol Detector (CLAD). Mikuška et al. (2000) use a luminol solution that is specific to $\mathrm{NO}_{2}$ only and removes interference with $\mathrm{O}_{3}$ and Peroxy Acetyl Nitrate (PAN), by adding sodium ethylenediaminetetraacetate (EDTA) and Triton X100 to the luminol solution.

Section 2 gives a detailed description of the design of the instrument. The chemistry that is involved within the luminol solution is explained in Sect. 3. The calibration of the $\mathrm{NO}_{2}$ sonde can be found in Sect. 4. Section 5 shows a comparison of the $\mathrm{NO}_{2}$ sonde with an in situ monitor. The estimated uncertainty of the $\mathrm{NO}_{2}$ sonde is discussed in Sect. 6 . The measured $\mathrm{NO}_{2}$ profiles during the Cabauw Intercomparison campaign of Nitrogen Dioxide measuring Instruments (CINDI campaign) are presented in Sect. 7. Discussion and conclusions can be found in Sect. 8.

\section{Design of the instrument}

Figure 1 (left side) shows a picture of the $\mathrm{NO}_{2}$ sonde. The instrument is housed in a polystyrene (PS) foam box. PS is light in weight and a good insulator. The size of the PS box is $19 \times 19 \times 26 \mathrm{~cm}^{3}$. The inside of the PS box is painted black, so ambient light is absorbed and can not disturb the measurement. To have an extra light barrier the instrument is placed in a black cardboard box. A radio transmitter (Vaisala RS92 radiosonde) is attached to the outside of the PS box. The weight of the $\mathrm{NO}_{2}$ sonde is approx. $0.7 \mathrm{~kg}$, excluding the weight of the radio transmitter.

Figure 2 shows a schematic diagram of the design of the instrument. A luminol reservoir (containing $35 \mathrm{ml} \mathrm{lu}-$ minol solution) is shown on the right. The liquid pump moves the luminol solution to the reaction vessel. The liquid pump used is a small $\left(30 \times 15 \times 3.8 \mathrm{~mm}^{3}\right)$ piezoelectric diaphragm pump (Bartels microComponents mp6). The Teflon air pump, which is taken from an ozone sonde, forces the ambient air into the reaction vessel with a flow of $4 \mathrm{ml} / \mathrm{s}$. A smaller flow rate would lower the signal and a larger flow rate would push all the liquid out of the reaction vessel. Johnson et al. (2002) tested the efficiency of the ozone sonde pump while decreasing the pressure. They concluded that the efficiency is not affected due to pressure decrease in the troposphere.

The tubes connected to the air pump are also made of Teflon. The gas is leaving the Teflon tube by two holes of 


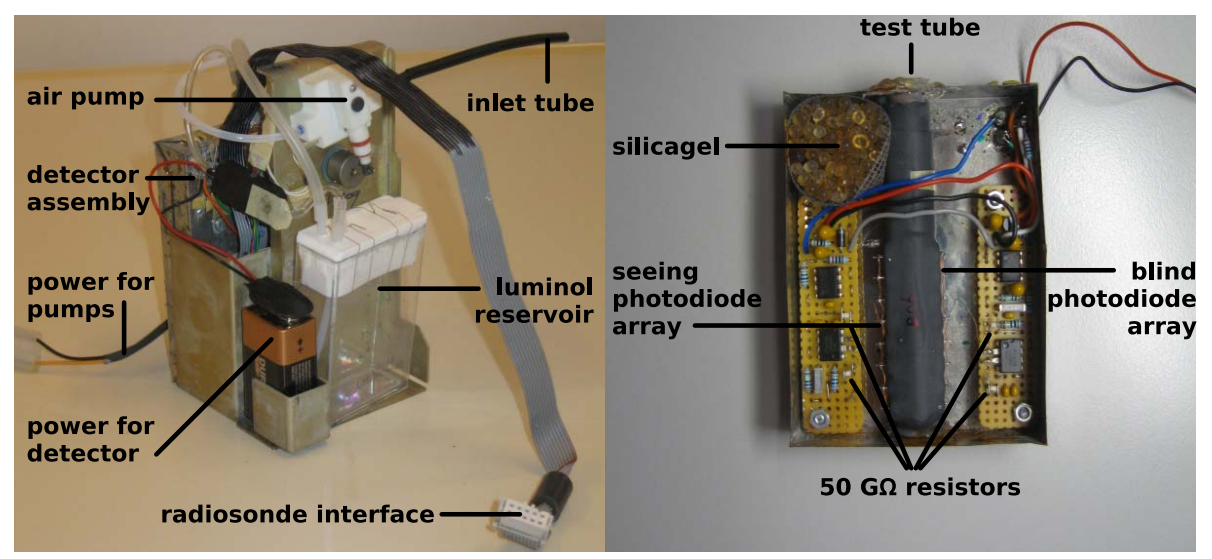

Fig. 1. The left panel shows all the components of an $\mathrm{NO}_{2}$ sonde without light protecting material. The right panel is a close-up of the detector.

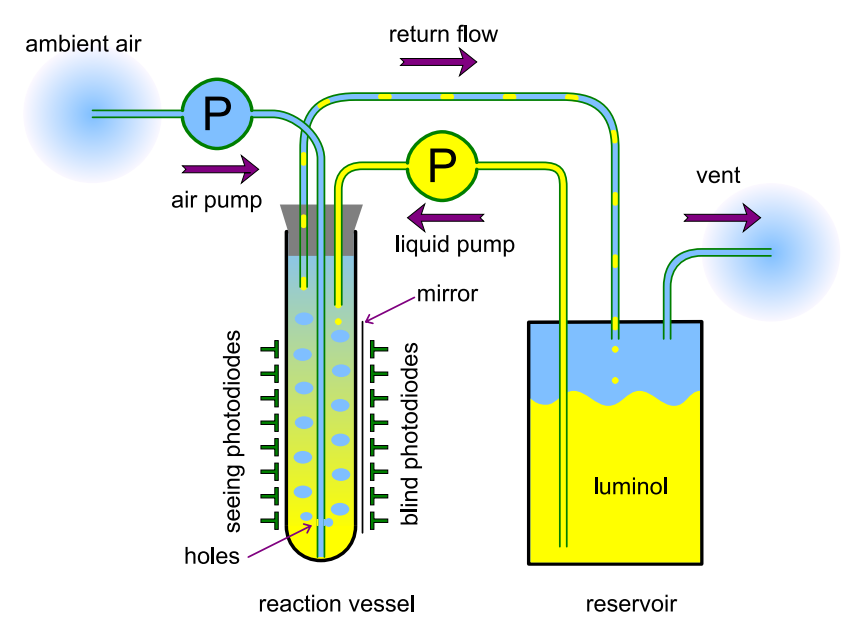

Fig. 2. The design of the $\mathrm{NO}_{2}$ sonde. The liquid pump moves the luminol solution to the reaction vessel in the centre. The Teflon air pump forces the air into the reaction vessel. The $\mathrm{NO}_{2}$ in the air reacts with the luminol and the emitted photons are detected by an array of silicon photodiodes (the seeing photodiodes). An aluminum mirror is placed on the opposite site to reflect the emitted photons back to the seeing photodiodes. An identical array of photodiodes, the blind array, is mounted behind the aluminum foil to measure and correct for - the effects discussed in Sect. 2.1. A copper wire is mounted in the reaction vessel to prevent electrostatic build-up.

$1 \mathrm{~mm}$ diameter. The $\mathrm{NO}_{2}$ in the gas flow reacts with the luminol solution, which emits blue/violet light at a wavelength of $425 \mathrm{~nm}$. The secondary function of the gas flow is to force the luminol solution out of the reaction vessel back to the luminol reservoir, so luminol is recycled continuously. The recycling of luminol is necessary to reduce acidification of the system by carbon dioxide $\left(\mathrm{CO}_{2}\right)$. Acidification can not be completely avoided because the luminol solution in the reservoir is continuously diluted with solution from the reaction vessel. The luminol solution contains Triton X-100 which causes foam and is able to escape in small proportions from the sealing of the luminol reservoir, therefore, absorption material is attached on the outside of the luminol reservoir. The volume of the luminol reservoir is $50 \mathrm{ml}$, but contains $35 \mathrm{ml}$ of the luminol solution.

\subsection{The detector}

The detector, as shown in Fig. 1 (right side), consists of a glass test tube, with an array of photodiodes on either side. Each array of photodiodes has its own circuit board for signal processing. The schematic diagram of the circuits is shown in Fig. 3. It shows from left to right the photodiodes (only 2 of the 8 are shown) who produce an electric current when exposed to light, a current to voltage converter, a low-pass $\mathrm{RC}$ (resistor-capacitor) filter with a time constant of $1 \mathrm{~s}$, to prevent under sampling of the signal by the data acquisition system (described in the next section) and a times 1 amplifier, to reduce the output impedance. The circuit has been designed to convert femtoamperes current from the photodiodes to millivolts at the output.

The circuit has been tested with an independent current source, to verify its sensitivity. A flashing light has been used to test its response to changing signals and the reflected light from two sources has been used to demonstrate that the output is linear to the intensity of light in the range from 10 to 2000 millivolts. The noise of the circuit is just below 1 millivolt when no photodiodes are attached. With the full array of 8 photodiodes the noise increases to 5 or 6 millivolts.

The circuit generates two unwanted signals. One is a dark current that differs from circuit to circuit, and is temperature dependent. This current can be characterised in the laboratory before launch, see Sect. 3. Furthermore, a signal is generated when the temperature of the photodiodes is changed. This might be caused by a heat flux through the photodiodes causes an electric current. Temperature changes inside the sonde can, however, not be prevented. This is why two arrays 


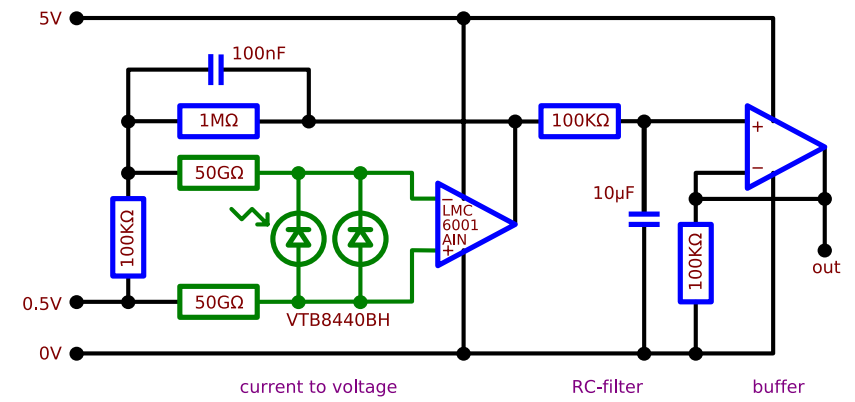

Fig. 3. The electronic circuit used in the detector. Note that only 2 of the 8 photodiodes are shown. The parts drawn in green are not mounted on the circuit board in order to minimize the effect of surface leakage currents.

of photodiodes have been used. The second (or blind) array has been mounted behind a piece of aluminum foil. The heat flux signal can be eliminated by subtracting the signals from both arrays. This function is performed as part of the post flight data processing.

\subsection{The radiosonde}

A Vaisala RS92SGP digital radiosonde is added as part of the package. This device measures ambient temperature, humidity and air pressure. Furthermore, it contains a GPS receiver, to measure its position, from which the wind speed and direction can be inferred. A radio transmitter sends the data to the ground station. The radiosonde is connected to a Vaisala RSA-11 ozone sonde interface. The device has four analogue inputs that are sampled once per second. Channels 3 and 4 are used to relay the signals from the $\mathrm{NO}_{2}$ detector. Channel 2 is dedicated to the measurement of the temperature inside the air pump. Channel 1 remains unused in the current design, but could be used for an additional ozone sensor. Laboratory studies have shown that the response time of the chemical reaction is in the order of one second. The RC filter in the amplifiers prevents under sampling of the $\mathrm{NO}_{2}$ profile. With an ascending speed of $5 \mathrm{~m} / \mathrm{s}$ and a read-out frequency of once per second, the resulting resolution of the $\mathrm{NO}_{2}$ profile is, thus, in the order of $5 \mathrm{~m}$.

\section{The luminol solution}

The $\mathrm{NO}_{2}$ sonde makes use of a chemical reaction called chemiluminescence. Chemiluminescence is an exothermic reaction, but instead of heat, light is emitted. The basic ingredient for this reaction is luminol, which gets in exited state when it reacts with $\mathrm{NO}_{2}$, and emits light of approximately $425 \mathrm{~nm}$ when decaying. The amount of light that is emitted is correlated to the $\mathrm{NO}_{2}$ concentration. The aqueous luminol solution contains an additional number of chemical compounds to make the luminol solution specific to $\mathrm{NO}_{2}$.
The chemical compounds and their function are listed and described below.

- Potassium hydroxide $(\mathrm{KOH})$ allows the luminol to dissolve in water by changing its polarity. White et al. (1963) studied the chemical reaction of luminol with $\mathrm{O}_{2}$. They argued that the reaction of the hydroxide ion $\left(\mathrm{OH}^{-}\right)$with luminol is the first step of the reaction, see Eq. (1).

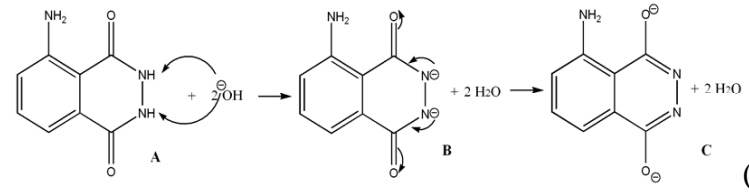

Deprotonation (A, Eq. 1) occurs when the strong base $\left(\mathrm{OH}^{-}\right)$reacts with the weak acid secondary amino groups $(-\mathrm{NH})$ forming a negative charge on the carbonyl oxygen $(-\mathrm{C}=\mathrm{O})$ to form what is known as an enolate (C, Eq. 1). The enolate anion is stabilized by resonance. The next step of the $\mathrm{NO}_{2}$-luminol reaction is not well understood. Maeda et al. (1980) reported that in the absence of $\mathrm{KOH}$ in luminol solution, no chemiluminescence was observed. When the concentration of $\mathrm{KOH}$ exceeded $10^{-5} \mathrm{~mol} / \mathrm{l}$ chemiluminescence was detected and the intensity was increased with the increase of $\mathrm{KOH}$ concentration.

- Sodium sulphite $\left(\mathrm{Na}_{2} \mathrm{SO}_{3}\right)$ is an anti-oxidant and is capable to capture sulphur dioxide $\left(\mathrm{SO}_{2}\right)$ and ozone $\left(\mathrm{O}_{3}\right)$. Wendel et al. (1983) discovered that $\mathrm{Na}_{2} \mathrm{SO}_{3}$ increases the duration of the stable period of the luminol solution. $\mathrm{Na}_{2} \mathrm{SO}_{3}$ also increases the emitted light signal, as shown in Fig. 4b, which is consistent with the results of Maeda et al. (1980).

- Ethanol makes the luminol solution more specific to $\mathrm{NO}_{2}$. Wendel et al. (1983) discovered that the addition of a primary alcohol - in their case methanol increased the sensitivity and specificity for $\mathrm{NO}_{2}$. The signal doubled at a concentration of $0.05 \% \mathrm{v} / \mathrm{v}$ and then decreased at higher concentrations. An advantage of using ethanol, which is also a primary alcohol, is that it is less harmful than methanol. Nguyen et al. (2006) also saw an increase in the light signal when using a luminol solution with a primary alcohol. Why the primary alcohol makes the luminol solution more specific to $\mathrm{NO}_{2}$ is not well understood.

- Sodium EDTA (ethylenediaminetetraacetate) is a complex former. Mikuška et al. (2000) claim that sodium EDTA is amplifying the functioning of $\mathrm{Na}_{2} \mathrm{SO}_{3}$. It makes the removal of $\mathrm{O}_{3}$ and PAN more efficient. The preferred solution of Mikuška et al. (2000) lowers the interference of $\mathrm{O}_{3}$ (mixing ratio 50 ppbv $\mathrm{NO}_{2}$ with $170 \mathrm{ppbv} \mathrm{O}_{3}$ ) to $0.2 \%$ of the total signal and lowers PAN interference (mixing ratio 50 ppbv $\mathrm{NO}_{2}$ with 

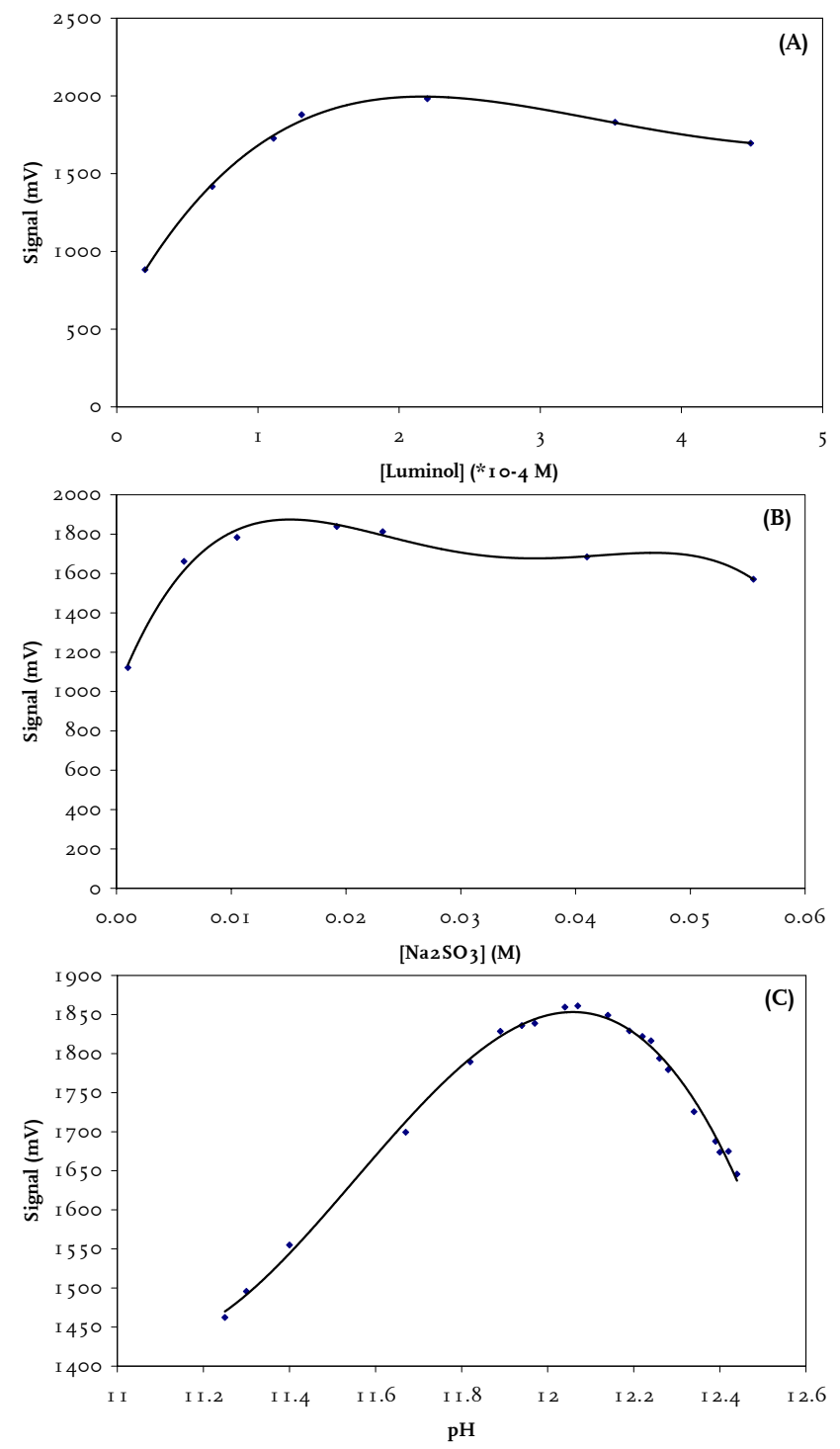

Fig. 4. Optimum concentration experiment for luminol (A), $\mathrm{Na}_{2} \mathrm{SO}_{3}$ (B) and $\mathrm{KOH}(\mathbf{C})$. (A) and (B) show signal (mV) versus concentration $(\mathrm{M}=\mathrm{mol} / \mathrm{l}),(\mathrm{C})$ shows signal $(\mathrm{mV})$ versus $\mathrm{pH}$ value. A constant concentration of 1.4 ppmv $\mathrm{NO}_{2}$ is used. The standard deviation of the measurements is on the order of $20 \mathrm{mV}$. The black line is a 4th order polynomial fit. The optimal concentration ranges are shown in Table 1.

81 ppbv PAN) to $1.2 \%$ of the signal (in combination with Triton X-100).

- Triton X-100 (4-octylphenol polyethoxylate) makes the luminol reaction more specific to $\mathrm{NO}_{2}$. Triton $\mathrm{X}-100$ decreases the surface tension, thereby enhancing the contact surface between air and liquid. Mikuška et al. (2000) argued that the enhancement of $\mathrm{NO}_{2}$ response arises from an increase in the concentration of luminol molecules at the surface of triton micelles. (A micelle is an aggregate of surfactant molecules dispersed in a liquid collide. A micelle in an aqueous solution forms an aggregate with the hydrophilic "head" regions in contact with surrounding solvent, isolating the hydrophobic single tail regions in the middle centre.) with subsequent diminution of vibrational quenching of excited species, which improves the fluorescent quantum yield of excited luminol. A radical molecule like $\mathrm{NO}_{2}$, with an unpaired electron, probably provides different electrostatic interactions with triton micelles in comparison with those by $\mathrm{O}_{3}$ and PAN that have no unpaired electron in the molecule.

- Oxygen is needed to activate the $\mathrm{NO}_{2}$ luminol reaction. Without oxygen, luminol does not emit light when exposed to $\mathrm{NO}_{2}$. Adding oxygen is only relevant for laboratory studies, as the ambient air contains sufficient oxygen for the reaction.

\subsection{Optimizing the luminol solution}

The chemicals that are listed above can be categorised into two groups; the reaction group (luminol, $\mathrm{KOH}, \mathrm{Na}_{2} \mathrm{SO}_{3}, \mathrm{O}_{2}$ ) and the protecting group $\left(\mathrm{Na}_{2} \mathrm{SO}_{3}\right.$, Triton X-100, $\mathrm{Na}$ EDTA, ethanol). The chemicals listed in the reaction group fulfil an important role in the luminol- $\mathrm{NO}_{2}$ reaction and the chemicals in the protecting group lower the interference of other strong oxidizers like PAN and $\mathrm{O}_{3}$.

The chemicals in the reaction group are optimized with respect to the light signal. This is done in an iterative process by varying the concentration of one component while holding the concentrations of all the other compounds constant around their optimum values, as found in a previous iteration step. The setup of this experiment is the same as in Fig. 2, where the ambient air was replaced with $\mathrm{NO}_{2}$ from a gas cylinder (10 ppmv $\mathrm{NO}_{2}$ in $\mathrm{N}_{2}$ ), mixed with $\mathrm{CO}_{2}$-free air to an $\mathrm{NO}_{2}$ concentration of 1.4 ppmv. Chemicals were added to the luminol reservoir. Note that for the optimizing experiments, an $\mathrm{NO}_{2}$ concentration of $1.4 \mathrm{ppmv}$ is used, which is much higher than what is typically observed in the atmosphere (ppbvs).

The molar concentration of the chemicals is expressed in $\mathrm{M}(\mathrm{mol} / \mathrm{l})$ units. Figure 4 shows the measured light signal as a function of concentration of the chemicals in the reaction group, luminol, $\mathrm{Na}_{2} \mathrm{SO}_{3}$ and $\mathrm{KOH}$ (top to bottom). The largest light signal is reached for a luminol concentration between $1 \times 10^{-4} \mathrm{M}$ and $2 \times 10^{-4} \mathrm{M}$. For larger luminol concentrations the light signal decreases again, probably as a result of self-absorption. The optimum $\mathrm{Na}_{2} \mathrm{SO}_{3}$ concentration is between 0.01 and $0.02 \mathrm{M}$ and the optimum $\mathrm{pH}$ value is between 12 and 12.2, corresponding to $\mathrm{KOH}$ concentrations between $0.01 \mathrm{M}$ and $0.016 \mathrm{M}$.

Table 1 gives an overview of optimal concentration ranges of the luminol solution and the standard concentrations actually used in this paper. The optimal luminol solution is the one which gives the highest light signal. The standard 
Table 1. Chemical compounds and concentrations used in the aqueous solution of luminol. The second column shows the optimal concentration range for the chemical compounds. The concentrations $(\mathrm{M}=\mathrm{mol} / \mathrm{l})$ that are applied in this paper are shown in the third column. The standard solutions have a higher than optimal concentration for potassium hydroxide, which is chosen to compensate for the effect of acidification by carbon dioxide. See Sect. 3 for more details.

\begin{tabular}{lll}
\hline Chemical compound & Optimal concentration range & $\begin{array}{l}\text { Standard } \\
\text { concentration }\end{array}$ \\
\hline Luminol & $1 \times 10^{-4} \mathrm{M}-2 \times 10^{-4} \mathrm{M}$ & $1 \times 10^{-4} \mathrm{M}$ \\
Sodium sulphate & $0.01 \mathrm{M}-0.02 \mathrm{M}$ & $0.02 \mathrm{M}$ \\
Potassium Hydroxide & $0.01 \mathrm{M}-0.016 \mathrm{M}(\mathrm{pH}: 12-12.2)$ & $0.03 \mathrm{M}(\mathrm{pH}: 12.5)$ \\
Sodium EDTA & $2 \times 10^{-4} \mathrm{M}$ & $2 \times 10^{-4} \mathrm{M}$ \\
Triton X100 & $0.02 \% \mathrm{v} / \mathrm{v}$ & $0.02 \% \mathrm{v} / \mathrm{v}$ \\
Ethanol & $0.05 \% \mathrm{v} / \mathrm{v}$ & $0.05 \% \mathrm{v} / \mathrm{v}$ \\
\hline
\end{tabular}

concentration of $\mathrm{KOH}$ used in the flying sondes is slightly higher in an attempt to reduce the effect of acidification (discussed below) and, hence, lengthen the time the sensor can be used.

\subsection{Acidification of the luminol solution}

When the $\mathrm{NO}_{2}$ sonde is measuring ambient air, carbon dioxide $\left(\mathrm{CO}_{2}\right)$ will acidify the luminol solution (already suggested by Maeda et al., 1980). The relevant reactions are:

$\mathrm{CO}_{2}+\mathrm{KOH} \longrightarrow \mathrm{KHCO}_{3}$

$\mathrm{KHCO}_{3}+\mathrm{KOH} \longrightarrow \mathrm{K}_{2} \mathrm{CO}_{3}+\mathrm{H}_{2} \mathrm{O}$

Figure 5 shows the degradation of the $\mathrm{pH}$ as a function of time. The $\mathrm{pH}$ measurements were recorded at surface pressure, by mixing ambient air and $\mathrm{NO}_{2}$ from the gas cylinder (ISO 17025 reliable, 10 ppmv $\mathrm{NO}_{2}$ and $99.999 \% \mathrm{~N}_{2}$ ) to a known $\mathrm{NO}_{2}$ concentration (1.4 ppmv). The flow rate of the Teflon air pump is the same as for the other experiments: $4 \mathrm{ml} / \mathrm{s}$. The standard luminol solution is used for this experiment (see Table 1). In Sect. 3.1, it was shown that a $\mathrm{pH}$ between 12 and 12.2 gives the optimal light signal. In sonde flights the $\mathrm{pH}$ is initially brought to 12.5 , to have an extended measuring time without a large degradation of the light signal. Also a luminol reservoir has been added to the sonde, so it can operate for about $2.5-3 \mathrm{~h}$ in a $\mathrm{pH}$ range of 12.5-11.6. Figure $4 \mathrm{c}$ shows that for this $\mathrm{pH}$ range the signal variation is less than $10 \%$. The sonde data is corrected for the acidification using parameterizations of $\mathrm{pH}$ as a function of time and signal as a function of $\mathrm{pH}$, based on the measurements from Figs. $4 c$ and 5, respectively (see Sect. 4). The acidification rate is determined at ground pressure and it will probably be smaller at higher altitudes because the $\mathrm{CO}_{2}$ partial pressure will be lower. This means that it might take even longer than 2.5-3 $\mathrm{h}$ before the $\mathrm{pH}$ drops below 11.6.

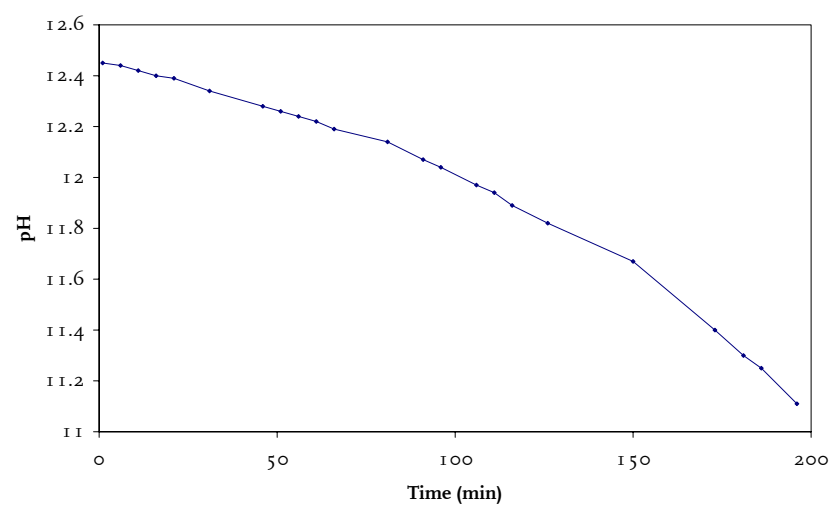

Fig. 5. Laboratory measurements of the $\mathrm{pH}$ as function of time. Acidification is caused by $\mathrm{CO}_{2}$, see Sect. 3.2. The measurement points are connected with straight lines.

\subsection{Nonlinearity issues}

Several authors have reported a nonlinear response of liquidphase chemiluminescence detectors, in the 0 to 3 ppbv range. Mikuška et al. (2000) shows that the nonlinearity depends on the chemical composition of the luminol solution, while Pisano et al. (1996) claim that the nonlinearity differs from instrument to instrument. Kelly et al. (1990) reported a change of sensitivity of his detector over time, and hints at a possible dependence on the age of the chemicals used. The reported nonlinearity's would, however, lead to corrections of less than $1 \mathrm{ppbv}$.

In this study the linearity problem has been investigated in the RIVM calibration facility. This calibration was performed at room temperature $\left(20^{\circ} \mathrm{C}\right)$ and ground pressure only. The air used in this experiment was from an ISO 17025 reliable cylinder $\left(10 \mathrm{ppmv} \mathrm{NO}_{2}, 99.999 \% \mathrm{~N}_{2}\right)$, mixed with clean air containing $\mathrm{CO}_{2} . \mathrm{NO}_{2}$ mixing ratios of $0,1,2,4$, $8,16,32$ and $64 \mathrm{ppbv}$ were introduced to 8 prototypes of the $\mathrm{NO}_{2}$ sonde. The results for two of the sondes (F07, and the less sensitive F05) are shown in Fig. 7. F07 was clearly able to record $1 \mathrm{ppbv}$ of $\mathrm{NO}_{2}$, while no nonlinearity was evident.

Figure 7 shows that within the targeted measurement range the deviations from linearity are below $10 \%$ or $0.8 \mathrm{ppbv}$, which leads to the conclusion that the $\mathrm{NO}_{2}$ sonde linearity is a valid approximation.

\section{Calibration}

The calibration of the measured signal is performed using the relation:

$n=f_{(T, \mathrm{pH})} \times\left(S_{1}-S_{2}-O\left(T_{\mathrm{d}}\right)\right)$,

where $n$ is the number density of $\mathrm{NO}_{2}, S_{1}$ is the measured signal in the seeing array of photodiodes and $S_{2}$ is the measured signal of the blind array of photodiodes, $O$ is an offset 


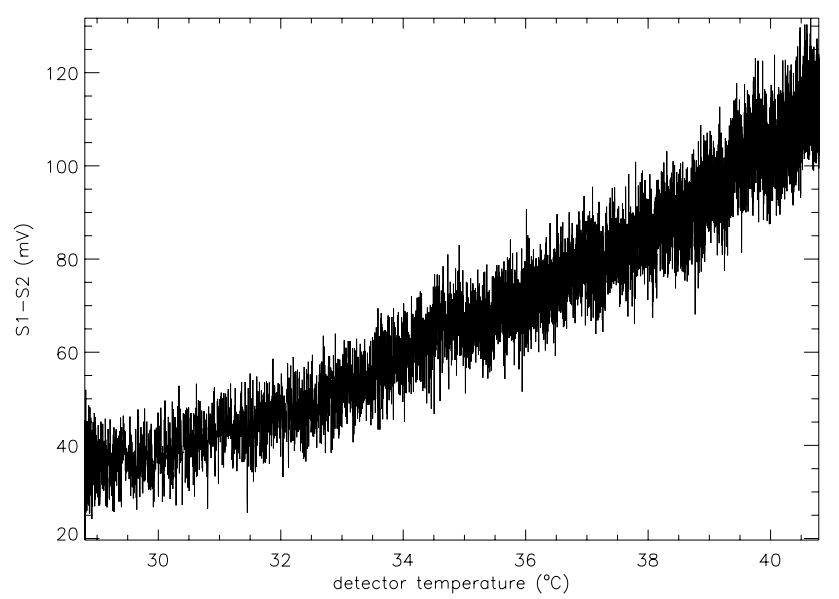

Fig. 6. The difference S1-S2 between the signals measured by the seeing and blind detector arrays, using water and ambient air, as a function of the detector temperature. The signal represents the offset $O$ in Eq. (4), for which the $\mathrm{NO}_{2}$ measurements need to be corrected.

which depends on the detector temperature $T_{\mathrm{d}}$ (see Fig. 6) and $f_{(T, \mathrm{pH})}$ is a scaling factor. The number density $n$ is converted to volume mixing ratio $v$ using the relation:

$v[\mathrm{ppbv}]=1.38 \times 10^{-12} \times n\left[\mathrm{~cm}^{-3}\right] \times \frac{T_{\mathrm{p}}[\mathrm{K}]}{p[\mathrm{hPa}]}$,

where $p$ is the pressure of the ambient air and $T_{\mathrm{p}}$ is the temperature inside the air pump.

The scaling factor $f_{(T, \mathrm{pH})}$ is almost constant during the first few hours of the measurement, meaning that the signal is almost linear with the amount of $\mathrm{NO}_{2}$.

The change in $\mathrm{pH}$ value during the measurement results in a small change in the scaling factor of about $10 \%$ in $2.5 \mathrm{~h}$ (see Sect. 3.2). The scaling factor also depends on the temperature of the solution, as can be seen in Fig. 8. The change in the scaling factor is $2.0 \%$ per degree Celsius for temperatures between $20^{\circ} \mathrm{C}$ and $40^{\circ} \mathrm{C}$, a typical temperature range inside the sonde box (air temperature outside the sonde box can of course be much lower). Figure 9 shows the temperatures of the pump, the liquid and the detector during a laboratory measurement as a function of time. After the initial few minutes, the temperatures behave very similar with a difference of 1 to $2^{\circ}$. Therefore, the pump temperature can be used to characterise the temperature correction.

Six sondes were launched during the CINDI campaign, June-July 2009 in Cabauw, the Netherlands (see Sect. 7). The temperature dependence of the offset was not characterised before the launch, so the offset is estimated to be a third order polynomial in time. This is an iterative fit through a selection of measurement points. At each iteration step those points are selected for which the difference to the polynomial is less than $1.5 \sigma$, starting with all measurement points and ending when the selection does not change

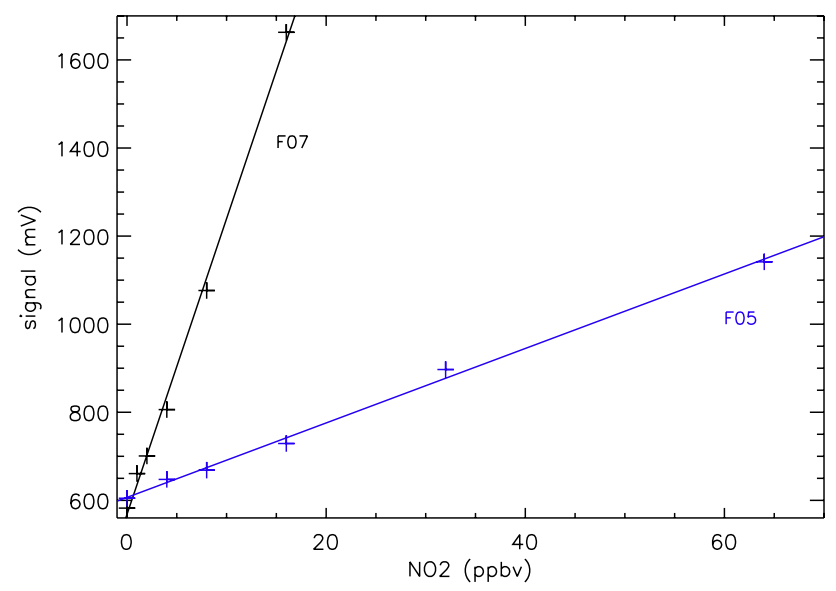

Fig. 7. The signal of the $\mathrm{NO}_{2}$ sonde detectors as a function of the amount of $\mathrm{NO}_{2}$ for two different versions of the detector, F05 and F07. F05 is designed for laboratory studies and is less sensitive, allowing larger $\mathrm{NO}_{2}$ concentrations. The solid lines are linear leastsquares fits.

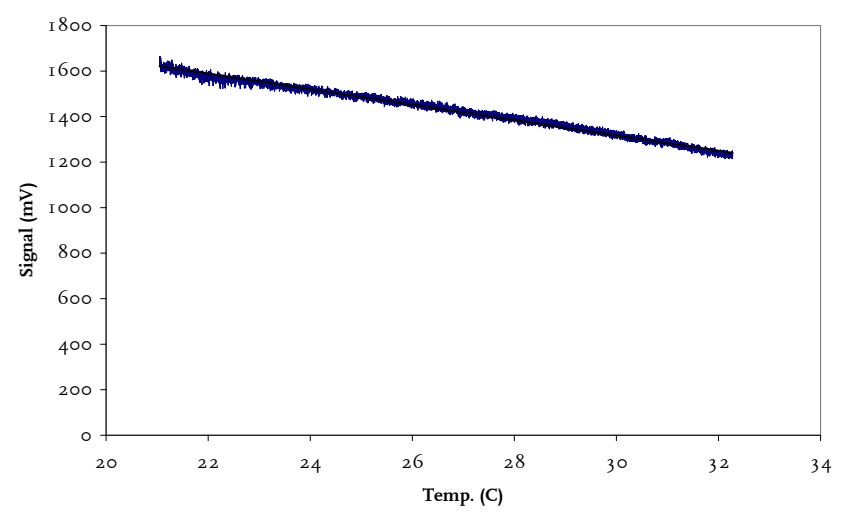

Fig. 8. Signal $(\mathrm{mV})$ of the seeing photodiodes as a function of temperature $\left({ }^{\circ} \mathrm{C}\right)$ in the luminol solution, for a constant amount of $\mathrm{NO}_{2}$ (blue). The black line represents a linear fit through the measured points. The signal decreases with $2.0 \%$ per degree Celsius.

anymore. Here $\sigma$ is the root mean square difference of the selected measurement points of the previous iteration to the fitted polynomial. This procedure could lead to an underestimation of $\mathrm{NO}_{2}$ in the free troposphere.

The scaling factor is determined using simultaneous in situ measurements by a Thermo Environmental Instruments (TEI 42 TL) chemiluminescence analyser with a Blue Light Converter, operated by EMPA during the CINDI campaign. Both instruments measure the ambient air at the same time, so that the amount of measured $\mathrm{NO}_{2}$ should be equal. The scaling factor at the launch is determined by dividing the average offset-corrected measurement signal of the sonde before launch by the interpolated $10 \mathrm{~min}$ values of the in situ monitor. The correction factor for the change in $\mathrm{pH}$-value during the flight is estimated to be $1-0.07 \times(t[\mathrm{~h}]-1.4)^{2}$, 


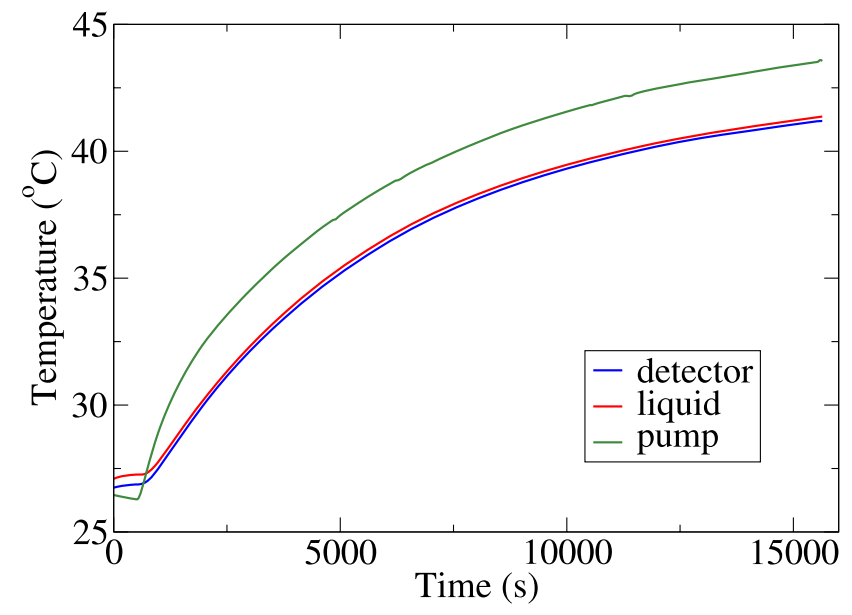

Fig. 9. Temperature $\left({ }^{\circ} \mathrm{C}\right)$ as function of time $(s)$ for the liquid in the reservoir (red), Teflon air pump (green) and detector (blue) during a laboratory measurement.

following from the data in Figs. 4 and 5, which is only a 1\% effect in the lowest kilometre.

\section{Comparison of the $\mathrm{NO}_{2}$ sonde with an in situ monitor}

The $\mathrm{NO}_{2}$ sonde is compared with an M200E Photolytic Analyser of Teledyne-API Inc. operated by RIVM. The M200E Photolytic Analyser measures $\mathrm{NO}$ and $\mathrm{NO}_{\mathrm{x}}$ $\left(\mathrm{NO}+\mathrm{NO}_{2}\right)$ and derives $\mathrm{NO}_{2}$ from it. The main goal of this comparison was to look if both instruments measure the same dynamical range in $\mathrm{NO}_{2}$ concentration variations during a certain period of time. Both instruments measured the $\mathrm{NO}_{2}$ concentration in ambient air at the same location on the roof of a building at approximately $20 \mathrm{~m}$ altitude, during rush hour. For this comparison a standard luminol solution is used (see Table 1).

The M200E Photolytic Analyser reports one-minute averaged $\mathrm{NO}_{2}$ values. The $\mathrm{NO}_{2}$ sonde data is also averaged over one minute in this comparison. As the sonde has not been calibrated with a known concentration of $\mathrm{NO}_{2}$, an assumption for the scaling factor had to be made. The scaling factor is chosen such that the average $\mathrm{NO}_{2}$ during the measuring period is equal for both instruments. The measurement of the $\mathrm{NO}_{2}$ sonde shown in Fig. 10 is corrected for temperature (see Sect. 4) and pH (see Sect. 3.2).

Four comparisons were made, but only one was without technical problems. The results are shown in Fig. 10. The technical difficulties that occurred for the other three comparisons were a broken liquid pump and leakage at the sealing of the reaction vessel. In the case of the broken liquid pump, the luminol solution was not recycled and this caused rapid acidification of the luminol solution, resulting in a loss of signal.
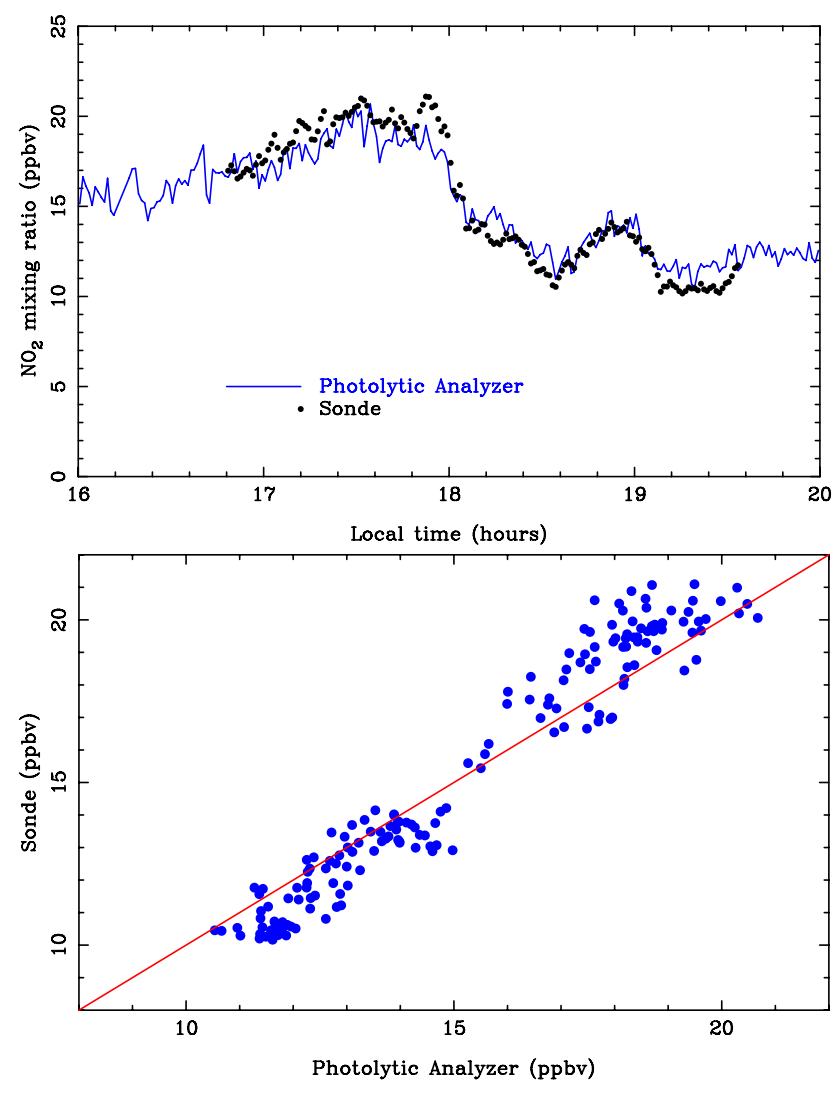

Fig. 10. Left: $\mathrm{NO}_{2}$ concentration measurements by the $\mathrm{NO}_{2}$ sonde (black dots) compared with those by the M200E photolytic analyser (blue line). Measurements were taken during the evening rush-hour in Bilthoven, The Netherlands. Right: scatter diagram of the same data.

Figure 10 shows that both instruments measure the same dynamical range of changing $\mathrm{NO}_{2}$ values and that variations of $1 \mathrm{ppbv}$ in $\mathrm{NO}_{2}$ are well captured. Noticeable are small differences between the two datasets, slowly changing with time, which suggest that the $\mathrm{NO}_{2}$ sonde has either a degrading sensitivity as a function of time or some nonlinearity in the scaling factor. This effect is still under investigation.

\section{Estimated uncertainty}

The root mean square (RMS) of the inter-comparison of the $\mathrm{NO}_{2}$ sonde with the M200E photolytic analyser of RIVM is $1 \mathrm{ppbv}$. This is an upper limit for the precision of the $\mathrm{NO}_{2}$ sonde measurements. The linearity study, described in Sect. 3.3, shows a maximum deviation of 0.8 ppbv or $10 \%$ when assuming linearity. We have characterised and eliminated the systematic effects caused by a variability in temperature and $\mathrm{pH}$ (Sect. 4). Unknown other systematic effects are artificially removed by scaling the sonde measurements to collocated independent in situ measurements. 


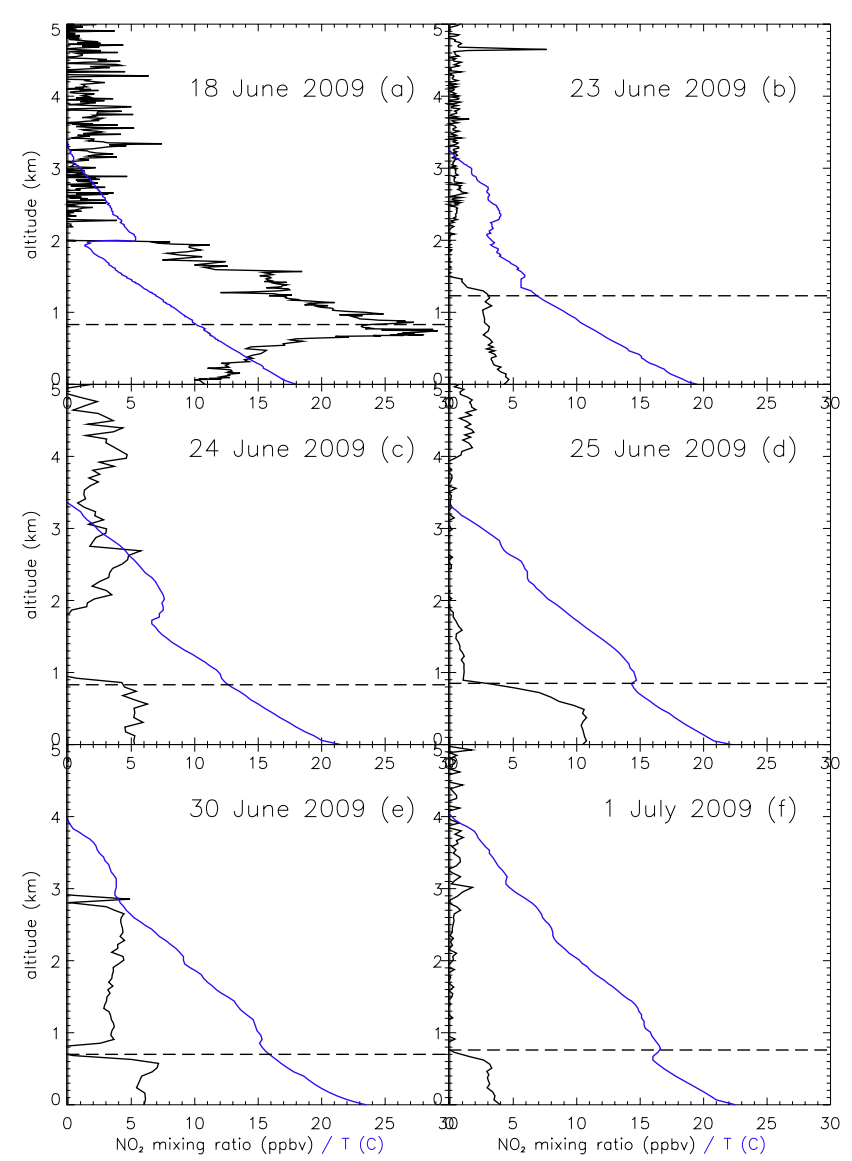

Fig. 11. Six vertical $\mathrm{NO}_{2}$ profiles measured during CINDI June/July 2009. On the $\mathrm{x}$-axis the $\mathrm{NO}_{2}$ volume mixing ratio and on the $\mathrm{y}$-axis the altitude $(\mathrm{km})$. The dashed horizontal lines indicate the boundary layer height above Cabauw around 10:30 UT, measured by the KNMI Ceilometer. The blue lines indicate the outside air temperature during the sonde flight.

This is done both for the on-ground comparison to the in situ monitor (Sect. 5) and for the sondes launched during the CINDI campaign (Sect. 7). For the CINDI sondes we have not been able to characterise the temperature dependent offset before launch. The estimate used for this offset, as described in Sect. 4, can lead to an underestimation of $\mathrm{NO}_{2}$ in the free troposphere. This effect will disappear when the temperature dependencies are characterised for each individual detector before launch. A proper estimate of the uncertainty in flight can only be given if the sonde measurements are compared to an independent source of $\mathrm{NO}_{2}$ profile information.

\section{CINDI campaign}

During the CINDI campaign in June/July 2009, six $\mathrm{NO}_{2}$ sondes were launched and measured six vertical profiles of $\mathrm{NO}_{2}$. The launch site was located at Lopik, the Netherlands $\left(51.97^{\circ} \mathrm{N}, 4.93^{\circ} \mathrm{E}\right)$. Figure 11 shows the six profiles that were measured. All $\mathrm{NO}_{2}$ sondes were launched at approximately 10:30 UTC, or 12:30 LT (local time). The $\mathrm{NO}_{2}$ sondes were treated with clean air just before launch, to determine the dark current of the detector. The $\mathrm{NO}_{2}$ sondes were scaled to in situ measurements performed by EMPA (TEI 42 TL chemiluminescence analyser, with BLC) just before launch. The target vertical velocity of the sonde flights was $5 \mathrm{~m} / \mathrm{s}$. The response of the $\mathrm{NO}_{2}$ sonde to changing $\mathrm{NO}_{2}$ concentrations is $1 \mathrm{~s}$, giving a resolution of $5 \mathrm{~m}$. In Fig. 11, the boundary layer heights are clearly visible in the profiles. They are in good agreement with boundary layer heights determined from meteorological measurements at Cabauw (LD40 Ceilometer, backscatter profiles).

The first $\mathrm{NO}_{2}$ sonde was launched on 18 June 2009, Fig. 11a. This profile shows a maximum $\mathrm{NO}_{2}$ concentration around $930 \mathrm{~m}$ altitude and a clear top of the boundary layer at $2 \mathrm{~km}$. Its vertical resolution is higher than that of the other sondes, because it had a smaller vertical velocity.

The profile of 23 June 2009 (Fig. 11b) shows at an altitude of $4.8 \mathrm{~km}$ a peak in $\mathrm{NO}_{2}$ concentration. This peak could have been caused by a layer of airplane exhaust.

The profile of 30 June 2009 (Fig. 11c) shows a second $\mathrm{NO}_{2}$ layer $(1-3 \mathrm{~km})$ above the boundary layer $(0-1 \mathrm{~km})$. The origin of this "second layer" could not be determined from meteorological measurements at Cabauw.

\section{Discussion/conclusion}

The $\mathrm{NO}_{2}$ sonde is light in weight, cheap (disposable), energy efficient and not dangerous for the environment. The sonde has a fast response to changing $\mathrm{NO}_{2}$ concentrations which results in an unsurpassed vertical resolution of $5 \mathrm{~m}$. It measures in the range $1-100 \mathrm{ppbv}$. The $\mathrm{NO}_{2}$ sonde can measure under all weather conditions irrespective of the amount of clouds.

The $\mathrm{NO}_{2}$ sonde developed at KNMI has demonstrated its capability to measure in situ $\mathrm{NO}_{2}$ profiles in the lower atmosphere. Six profiles have been collected during the CINDI campaign in June/July 2009. The top of the boundary layer is clearly visible in the profiles and are in good agreement with boundary layer heights determined from meteorological measurements at Cabauw (backscatter profiles, LD40 Ceilometer).

Comparison with the M200E Photolytic Analyser shows that variations of 1 ppbv in $\mathrm{NO}_{2}$ are well captured. Both instruments measure the same dynamical range in $\mathrm{NO}_{2}$ variations in ambient air during a $2.5 \mathrm{~h}$ period. The estimated uncertainty of the $\mathrm{NO}_{2}$ sonde measurements is $1 \mathrm{ppbv}$, after the correction for temperature dependence and $\mathrm{pH}$ and after artificially removing all remaining unknown systematic effects by scaling the on-ground measurements to collocated, independent, in situ measurements. The measurements during CINDI may underestimate the $\mathrm{NO}_{2}$ values in the free 
troposphere, because the temperature dependant offset was not well characterised before the launch. This is expected to improve for further launches.

Further validation of the $\mathrm{NO}_{2}$ sonde is desirable and can be done by a comparison with the $\mathrm{NO}_{2}$ LIDAR.

The $\mathrm{NO}_{2}$ sonde can measure for approximately $2.5-3 \mathrm{~h}$. After that time the solution becomes increasingly acid due to $\mathrm{CO}_{2}$. Longer continuous measurements can be established by using a good buffer solution or a $\mathrm{CO}_{2}$ scrubber to keep the $\mathrm{pH}$ constant.

In theory, the sonde can make $\mathrm{NO}_{2}$ profiles up to the stratosphere, but because the temperature within the sonde rises up to $40^{\circ} \mathrm{C}$, the luminol solution begins to boil at low pressure. To prevent this in the near future, a redesign of the pump drivers is required.

Acknowledgements. The authors would like to thank Jan Venema and Daan Swart of RIVM for making their calibration facility available to us and their help in making the calibration measurements. Ruud Hoogeveen from SRON is gratefully acknowledged for sharing his knowledge, which we used to develop the detector that is applied in the $\mathrm{NO}_{2}$ sonde. All CINDI colleagues, especially Dominik Brunner and Yipin Zhou from EMPA and Enno Peters from the University of Bremen, are gratefully acknowledged for making their datasets available for comparisons. We want to thank Piet Stammes (KNMI) and Stijn Berkhout (RIVM) for useful comments on this paper. Special thanks to Henk Klein Baltink for providing us with boundary layer heights. We acknowledge the support of the European Commission through the GEOmon (Global Earth Observation and Monitoring) Integrated Project under the 6th Framework Program (contract number FP6-2005Global-4-036677). This work has partly been financed by the Netherlands Space Organisation via the SCIAVISIE project.

Edited by: A. Apituley

\section{References}

Boersma, K. F., Jacob, D. J., Bucsela, E. J., Perring, A. E., Dirksen, R., van der A, R. J., Yantosca, R. M., Park, R. J., Wenig, M. O., Bertram, T. H., and Cohen, R. C.: Validation of OMI tropospheric $\mathrm{NO}_{2}$ observations during INTEX-B and application to constrain $\mathrm{NO}_{\mathrm{x}}$ emissions over the eastern United States and Mexico, Atmos. Environ., 42, 4480-4497, 2008.

Hasinoff, L. C.: Vertical profiles of $\mathrm{NO}_{2}$ and $\mathrm{O}_{3}$ at Kejimkujik National Park, Nova Scotia, Thesis, Graduate programme in Chemistry York University, North York, Ontario, 1997.

Johnson, B. J., Oltmans, S. J., Vömel, H., Smit, H. G. J., Deshler, T., and Kröger, C.: Electrochemical concentration cell (ECC) ozonesonde pump efficiency measurements and tests on the sensitivity to ozone of buffered and unbuffered ECC sensor cathode solutions, J. Geophys. Res., 107(D19), 4393, doi:10.1029/2001JD000557, 2002.
Kebabian, P. L., Herndon, S. C., and Freedman, A.: Detection of nitrogen dioxide by cavity attenuated phase shift spectroscopy, Anal. Chem., 77, 724-728, 2005.

Kelly, T. J., Spicer, C. W., and Ward, G. F.: An Assessment of the luminol chemiluminescence technique for measurement of $\mathrm{NO}_{2}$ in ambient air, Atmos. Environ., 24A(9), 2397-2403, 1990.

Li, Y. Q., Demerjian, K. L., Zahniser, M. S., Nelson, D. D., McManus, J. B., and Herndon, S. C.: Measurement of formaldehyde, nitrogen dioxide, and sulphur dioxide at Whiteface Mountain using a dual tunable diode laser system, J. Geophys. Res., 109, D16S08, doi:10.1029/2003JD004091, 2004.

Maeda, Y., Aoki, K., and Munemori, M.: Chemiluminescence Method for the Determination of Nitrogen Dioxide, J. Anal. Chem. Soc., 52, 307-311, 1980.

Matsumoto, J., Hirokawa, J., Akimoto, H., and Kajii, Y.: Direct measurement of $\mathrm{NO}_{2}$ in the marine atmosphere by laserinduced fluorescence technique, Atmos. Environ., 35, 28032814, doi:10.1016/S1352-2310(01)00078-4, 2001.

Mikuška, P. and Večeřa, Z.: Effect of complexones and tensides on selectivity of nitrogen dioxide determination in air with a chemiluminescence aerosol detector, Anal. Chim. Acta, 410, 159-165, 2000.

Mitrayana, Pierera, T., Moeskops, B. W. M., Persijn, S., Naus, H., Harren, F. J. M., Wasono, M. A. J., -Muslim, and Rochmah, W.: Diode-laser based photo-acoustic spectroscopy in atmospheric $\mathrm{NO}_{2}$ detection, Berkala Ilmiah MIPA, Vol. 17(3), 2007.

Nguyen, D. H., Berry, S., Geblewicz, J. P., Couture, G., and Huynh, P.: Chemiluminescent detection of explosives, narcotics, and other chemical substances, US patent no.: US6,984,524 B2, 2006.

Parrish, D. D., Hahn, C. H., Fahey, D. W., Williams, E. J., Bollinger, M. J., Hübler, G., Buhr, M. P., Murphy, P. C., Trainer, M., Hsie, E. Y., Liu, S. C., and Fehsenfeld, F. C.: Systematic Variations in the Concentration of $\mathrm{NO}_{x}\left(\mathrm{NO}\right.$ plus $\left.\mathrm{NO}_{2}\right)$ at Niwot Ridge, Colorado, J. Geophys. Res., 95(D2), 1817-1836, 1990.

Pisano, J. T. and Drummond, J. W.: A Lightweight $\mathrm{NO}_{2}$ Instrument for Vertical Height Profiles, J. Atmos. Ocean. Tech., 13, 400, 1996.

Platt, U. and Pierera, T.: Direct measurements of atmospheric $\mathrm{CH}_{2} \mathrm{O}, \mathrm{HNO}_{2}, \mathrm{NO}_{2}$, and $\mathrm{SO}_{2}$ by differential optical absorption in the near UV, J. Geophys. Res.-Oceans, 85, 7453-7458, 1980.

Sitnikov, N. M., Sokolov, A. O., Ravegnani, F., Yushkov, V. A., and Ulanovskiy, A. E.: A chemiluminescent Balloon-Type Nitrogen Dioxide Meter for Tropospheric and Stratospheric Investigations (NaDA), Instrum. Exp. Tech., 48(3), 400-405, 2005.

Steinbacher, M., Zellweger, C., Schwarzenbach, B., Bugmann, B., Ordoñez, C., Prevot, A. S. H., and Hueglin, C.: Nitrogen dioxide measurements at rural sites in Switzerland: Bias of conventional measurements techniques, J. Geophys. Res., 112, D11307, doi:10.1029/2006JD007971, 2007.

Wendel, G. J., Stedman, D. H., and Cantrell, C. A.: Luminol - based Nitrogen Dioxide Detector, Anal. Chem., 55, 937-940, 1983.

White, E. H., Zafiriou, O., Kägl, H. H., and Hill, H. M.: Chemiluminescence of Luminol: The Chemical Reaction, J. Am. Chem. Soc., 86, 940-941, 1964. 